metal substrates. Of particular interest in this session, perhaps, was the work on tho use of metal chelates as eatalysts for the polymerization of $\alpha$-olefins and olefin oxides. The cross-linking studies are confined to one paper on reactions which occur on heating films of polyvinyl alcohol; similarly, only one paper on the reaction of certain coatings with metal substrates is included in this session.

The third session takes as its theme the thermal degradation of polyvinyl chloride and other polymers with, in some cases, particular reference to the modification of certain physical properties by heat treatments. Of particular interest, perhaps, is the attempt to use gas-liquid chromatography in an analysis of the products and the light they throw on the structure of the polymers and copolymers.

The fourth and final session deals with the very difficult problem of examining the results of rheological measurements. Thus flow defects in fabrication are discussed in terms of the melting, homogenization, drawing, blowing and so on, by one author; and by another, flow defects in a commercial extruder are analysed in relation to their melt indices. These realistic studies of fabrication of polymers are supported by papers of a slightly more theoretical character where, for example, melt viscosities are examined in terms of a simple equation.

In general terms, this conference attempted to span a very wide range of polymer interests, with the result that no one subject was covered in depth and the sessions tended to be rather heterogeneous. This, of course, has the advantage that there are some papers of interest to most workers in the polymer field, but it is possible that a reader may be a little disappointed that his particular area is not discussed in sufficient detail. R. H. Perers

\section{ISOTOPES AND SOIL STUDIES}

\section{Isotope Studies on the Nitrogen Chain}

(Proceedings of the Symposium on the Use of Isotopes in Studies of Nitrogen Metabolism in the Soil-Plant-Animal System, Vienna, August 28-September 1, 1967. Proceedings Series.) Pp. 343. (International Atomic Energy Agency: Vienna; HMSO: London, 1968.) 181 schillings; 49s. 6d.; \$; $28 \mathrm{DM}$.

THE symposium of which this volume is the record is one of a series convened by the International Atomic Energy Agency and the Food and Agriculture Organization of the United Nations, together with the Joint Committee on Applied Radioactivity. It is stated in the foreword that the purpose of the symposium was to bring together specialists in soil science, plant physiology and animal nutrition to discuss the application of nuclear techniques to studies of nitrogen motabolism, and to stimulate further co-operation. There is no doubt that the symposium in bringing together workers in diverse but related fields has performed a very useful function. To attempt to limit it, however, to the application of nuclear techniques is much more questionable. While emphasis on techniques may be necessary in the earliest stages of development of these, the use of isotopic tracers is now so widespread that this approach is no longer desirable. In fact, the papers in the symposium illustrate this point very well. Several of them do not involve the application of nuclear techniques at all. Of the rest, some are concerned with the stable nuclide nitrogen-15, the others with various radioactive tracers, principally carbon-14 and sulphur-35.

A clearer indication of the scope of the symposium is given by the opening lecture, which is on the world's present and future resources of protein available for human nourishment, and the possibilities for utilizing these resources. This sets the theme for the whole programme, which consists of papers on various stages of the nitrogen chain from the soil via the plant to animals and man.

As is customary in this series, the papers are printed in the original language, French (2), Russian (4) or English (17), with an abstract and discussion in English. The volume has been printed by composition typing and photo-offset lithography for speed of publication. Some of the tables have very small print as a result, although, in general, the standard of reproduction of the tables and figures is adequate. Fortunately there are few photographs, the two which are included demonstrating, at least in my copy, that little useful purpose is served by them.

The opening lecture, in French, is a comprehensive account of protein sources, from land plants and animals to fish and other marine sources. Methods of increasing protein yield are discussed and an extensive bibliography is provided. Then follow nine papers on soil science and plant physiology. This section includes several studies of nitrogen fertilizer uptake, both in effects on plant growth and in relation to protein synthesis. In the section on animal physiology and nutrition, also of nine papers, considerablo attention is given to the importance of a diet which will supply the essential amino-acids in suitable proportions. The main emphasis in this section is on experiments of a biochemical nature. Three papers on techniques include a useful survey of methods of evaluation of nitrogen utilization together with details of techniques used by the authors. Finally, there is one paper on plant breeding in relation to protein quantity and quality.

Clearly a symposium of this kind, covering as it does such a wide field, will have few papers of direct interest for the specialist. It is of much greater value in providing an opportunity for research workers to meet, particularly in informal discussions. The published record is therefore only of secondary importance. It is useful, however, for all research workers to be reminded from time to time of the broader aspects of their work and this volume could well do this. For those not so closely associated with this field the extent and complexity of the whole chain involved in human nutrition are illustrated. The symposium, on the other hand, does not present a survey of isotopic techniques as such, and less emphasis could well have been laid on this aspect. R. P. Martin

\section{ECOSYSTEM FUNCTIONING}

\section{Functioning of Terrestrial Ecosystems at the Primary} Production Level

Edited by F. E. Eckardt. (Proceedings of the Copenhagen Symposium.) Pp. 516. (United Nations Educational, Scientific and Cultural Organization: Paris, 1968.) 948.

THE forty-five or so papers printed in this book were presented at a symposium held in 1965 under the joint auspices of Unesco and the Royal Academy of Science and Letters of Denmark, as part of the Unesco programme aimed at defining the scientific basis for the rational use of the biosphere. The announced (and laudablo) intention of this meeting was to study the functioning of the ecosystem "at the primary production level", but in the event we are confronted with a series of papers on the relation between growth and environment, frequently handled in terms of energy flow. One of the contributors to the discussions admits as much-"Now, this symposium is concerned with the relation of environment to plant growth." If we could accept a definition of onvironment as light, temperature, water and carbon dioxide, this meeting and its published proceedings must be rated a valuable and successful follow-up to other such gatherings as the Canberra conference. Many of the important people in the growth : environment world were there, and the papers are substantial and authoritative statements of research completed or then in progress, 